\title{
Evaluating the Congestion Relief Impacts of Public Transport in Monetary Terms
}

\author{
Md Aftabuzzaman, Graham Currie, Majid Sarvi \\ Monash University
}

\begin{abstract}
Traffic congestion is a major urban transport problem. Efficient public transport (PT) can be one of the potential solutions to the problem of urban road traffic congestion. Public transport systems can carry a significant amount of trips during congested hours, improving overall transportation capacity, and can release the burden of excess demand on congested road networks. This paper presents a comparative assessment of international research valuing the congestion relief impacts of PT. It explores previous research valuing congestion relief impacts and examines secondary evidence demonstrating changes in mode split associated with changes in public transport. The research establishes a framework for estimating the monetary value of the congestion reduction impacts of public transport. Congestion relief impacts are valued at between 4.4 and 151.4 cents (Aus\$, 2008) per marginal vehicle $\mathrm{km}$ of travel, with an average of 45.0 cents. Valuations are higher for circumstances with greater degrees of traffic congestion and also where both travel time and vehicle operating cost savings are considered. A simplified congestion relief valuation model is presented to estimate the congestion relief benefits of PT based on readily -available transport data. Using the average congestion valuation and mode shift evidence, the model has been applied to a number of cities to estimate the monetary value of the congestion relief impact of public transport. Overall, the analysis presents a simplified method to investigate the impact of public transport on traffic congestion.
\end{abstract}


Further research is warranted to develop a comprehensive approach for establishing a measure of the congestion relief impact of public transport.

\section{Introduction}

Road traffic congestion is a major urban transport problem (Cervero 1991; Downs 1992). Increasing demand for travel will compound the problem if appropriate solutions are not actively sought. Efficient public transport (PT) can be one of the potential solutions to the problem of urban road traffic congestion (Hyman and Mayhew 2002;; Pucher et al. 2007; Vuchic 1999).

This paper presents a comparative assessment of international research valuing the congestion relief impacts of PT. It explores previous research valuing congestion relief impacts and examines secondary evidence demonstrating changes in mode split associated with changes in public transport. The research establishes a framework for estimating the monetary value of the congestion reduction impacts of public transport. To illustrate findings, a theoretical model is presented where congestion impact evidence is applied to understand congestion relief impacts.

The paper is structured as follows. The next section $\neg$ outlines the methodological approaches adopted in previous research concerning PT and congestion relief impacts. In Section 3, valuations of PT congestion relief benefits are summarized from Australasian, European, and North American research. Section 4 synthesizes the evidence of congestion relief benefits to establish valuations of congestion relief impacts on a common currency and single-year basis. Section 5 reviews mode shift evidence associated with car and public transport. In Section 6, a simplified congestion relief valuation model is presented, and the research findings are illustrated by estimating congestion relief impacts for a number of global cities. The concluding section summarizes the key findings of the paper and provides some suggestions for further research.

\section{Review of Benefit Assessment Methodologies}

A range of studies have examined the economic benefits of public transport congestion relief impacts. This section reviews previous research related to the economic evaluation of congestion relief associated with public transport.

A literature review of quantitative approaches for measuring and valuing public transport benefits and disbenefits was undertaken by Cambridge Systematics and 
Apogee Research (1996). The review identified three main tools that are central to the assessment of public transport benefits and disbenefits:

- travel demand models

- transport cost analysis techniques

- transport sketch planning and impact spreadsheets

A report by ECONorthwest and PBQD (2002) provided practical methods in the framework of cost-benefit analysis for estimating the benefits and costs of a typical public transport project. The report noted that a public transport improvement affects the user costs of alternative modes due to the interconnected nature of the typical urban transport network. The report suggests that under congested conditions, even small changes in vehicle volumes can have significant effects on the performance of the roadway. Travel time and vehicle operating costs are affected and can be estimated as follows:

- Changes in travel time can be calculated from volume-delay relationships that are embedded in the traffic assignment element of transport planning models. These can be monetized using a standard value of time (as a percentage of standard average wage rate).

- Vehicle operating cost can be estimated from the information provided by motoring organizations (e.g., the American Automobile Association) that perform research calculating the cost of operating automobiles of various types.

Research on the economic implications of congestion was conducted by Weisbrod et al. (2001). Estimation of the economic cost savings for road users (the traditional user impacts) associated with urban roadway congestion reduction can be determined from the difference of user travel time and vehicle operating costs in base and project cases. Their methodology for estimating user travel time and vehicle operating costs can be described in the following steps:

1. Trip Data-It is first necessary to obtain zone-to-zone trips matrices to show the number of trips corresponding to each origin-destination pair of traffic analysis zones (TAZs).

2. Travel Time and Distance Data-Transport planning models typically include zone-to-zone matrices of travel distances and mean travel times. These travel time and distance data together with trip data can be used to calculate vehicles hours of travel and vehicle miles of travel. 
3. The components of unit travel costs (costs of driver time and vehicle operating expenses) are obtained from standard sources. Unit cost factors are multiplied by the travel time, distance, and trip data to calculate aggregate user time and expense costs.

The Australian Transport Council (2006) suggests a method for estimating decongestion benefits using the following three elements: (1) an estimate of the quantity of road traffic removed from the road system, (2) an estimate of the change in travel speed (by using a manual approach or a computerized travel demand model), and (3) a value of travel time for car occupants. Their method for estimating decongestion benefits is essentially the same as that in the New Zealand approach (Land Transport New Zealand 2005).

Beimborn et al. (1993), in reviewing the principles and issues for public transport benefit measurement, provided a framework for benefit analysis and described measurement techniques. Their study presented public transport benefits in the form of a benefit tree by dividing the benefits into four main groups (branches) and further subdividing them within four branches:

1. Public transport as an alternative-the value of having public transport available as a possible alternative (i.e., an option value).

2. Travel by public transport-the public transport trips resulting from a shift between auto and public transport and from trips by persons who could not otherwise travel.

3. Public transport and land use-the public transport accessibility that changes property value, preserves open space, affects interaction among people, and affects the efficiency of certain public services.

4. Public transport supply - the presence of public transport as an enterprise that employs people in its operation and construction.

Their study proposed that traffic congestion relief benefits for auto users in terms of travel time savings can be estimated through an enhanced consumer surplus technique. The enhanced consumer surplus can be estimated by using appropriate travel forecasting models in which the trip distribution and model split steps are based upon roadway disutilities that are appropriate for the amount of traffic congestion. The technique measures the decrease in disutility of travel in units of time (i.e., the increase of consumer surplus) for an alternative public transport system as compared to a base system. Again, travel time savings are converted to monetary units by multiplying by the value of time. 
An estimation of the congestion reduction effects of public transportation was made in a study of 85 cities (Schrank and Lomax 2005). The report determined the delay benefits by assuming the question "what if all transit riders were in the general traffic flow instead of on public transport?" The additional shifted traffic would clearly increase congestion on the road network. The size of additional roadway traffic was calculated by dividing the number of existing PT users by car occupancy factor. In the 85 North American urban areas studied, approximately 43 billion passenger-miles of travel were on public transport systems in 2003. Ridership ranged from 17 million in the small urban areas to about 2.7 billion in the very large areas. Overall, if riders did not use public transport systems, they were estimated to cause an additional roadway delay of approximately 1.1 billion hours (a $29 \%$ increase in delay) at an additional congestion cost of $\$ 18$ billion (US\$, 2005) (Table 1).

Table 1. Delay Increase if Public Transport (PT) Service were Eliminated - 85 Areas

\begin{tabular}{|l|l|l|l|l|l|}
\hline \multicolumn{3}{|c|}{} & \multicolumn{1}{|c|}{ Delay reduction due to public transport } \\
\hline $\begin{array}{c}\text { Population } \\
\text { group (number } \\
\text { of areas) }\end{array}$ & $\begin{array}{c}\text { average travel } \\
\text { (millions of } \\
\text { pax-miles) }\end{array}$ & $\begin{array}{c}\text { Annual delay } \\
\text { (millions of } \\
\text { hours) }\end{array}$ & $\begin{array}{c}\text { Delay } \\
\text { reduction } \\
\text { (millions of } \\
\text { hours) }\end{array}$ & $\begin{array}{c}\text { Percent of } \\
\text { base delay }\end{array}$ & $\begin{array}{c}\text { Saving } \\
\text { (US \$M) }\end{array}$ \\
\hline Very Large (13) & 2,718 & 2,526 & 919 & 36 & 15,289 \\
\hline Large (26) & 233 & 875 & 148 & 17 & 2,485 \\
\hline Medium (30) & 58 & 288 & 27 & 9 & 444 \\
\hline Small (16) & 17 & 34 & 2 & 4 & 25 \\
\hline Total (85 Areas) & $\mathbf{4 3 , 4 0 3}$ & $\mathbf{3 , 7 2 3}$ & $\mathbf{1 , 0 9 6}$ & $\mathbf{2 9}$ & $\mathbf{1 8 , 2 4 3}$ \\
\hline
\end{tabular}

Nelson et al. (2006) estimated both the total system benefit to PT users and congestion impact to motorists of PT in Washington, D.C. The study used a regional travel demand model and calculated the aggregate welfare change by reducing public transport supply to zero. The decline in traveler welfare minus the savings in operating costs was interpreted as a measure of benefits of the existing system. The study tested three scenarios: eliminating bus and rail separately, and eliminating both modes together. Based on the welfare change estimates and using the "shutting down both modes together" scenario, the study predicted motorists' congestion reduction benefits as $\$ 736$ million (US\$, 2000) annually. 
In summary, two principal measurement approaches are adopted in the literature, those based on transport models and those from other indirect approaches. These are summarized in Table 2.

\section{Table 2. Summary of Economic Estimation Methods for Congestion Reduction Impacts of Public Transport}

\begin{tabular}{|c|c|}
\hline Method & Description \\
\hline $\begin{array}{l}\text { Transport } \\
\text { System } \\
\text { Model }\end{array}$ & $\begin{array}{l}\text { Transport system models are used to simulate and forecast the effects of transport } \\
\text { facilities and services on trip generation, mode split, trip routing, travel times and } \\
\text { travel costs. The output from the model (the travel time savings in time units) is } \\
\text { multiplied by a value of time to quantify the benefits in monetary terms. }\end{array}$ \\
\hline $\begin{array}{l}\text { Indirect } \\
\text { measurement } \\
\text { technique }\end{array}$ & $\begin{array}{l}\text { Indirect measurement techniques measure the effects of existing transport } \\
\text { facilities and service through analysis of historical data/user impacts through } \\
\text { surveys of travelers, nearby businesses, or both as well as through secondary data. } \\
\text { As an example of the indirect measurement technique: } \\
\text { - Increase in road traffic congestion from the cessation of public transport = (The } \\
\text { number of passengers diverted to car / Car occupancy rate) * Average motor } \\
\text { vehicle trip distance * Estimated road decongestion benefit. } \\
\text { - Benefits to motorists who remain in the road system after an improved public } \\
\text { transport system = An estimate of the quantity of road traffic removed from } \\
\text { the road system * An estimate of changes in travel speed (a manual approach/ a } \\
\text { survey) * A value of travel time for car occupants. }\end{array}$ \\
\hline
\end{tabular}

\section{Summary of Congestion Relief Valuation Evidence}

This section reviews international evidence where public transport decongestion benefits were valued to better understand the range and types of impacts studied.

\section{Australasian Evidence}

Congestion relief associated with the provision of Sydney CityRail services was quantified by investigating the cost and benefits associated with the hypothetical cessation of CityRail services (Karpouzis et al. 2007). The study used a second best alternative mode approach. This assumed that journeys would divert from rail to road (about $53 \%$ to car, about $42 \%$ to bus) and walking (about $5 \%$ ). A traffic congestion relief benefit of 30.5 cents (Aus\$, 2007) per car kilometer and 104.0 cents (Aus\$, 2007) per bus kilometer was derived. The study estimated the total cost of additional congestion at $\$ 740.5$ million p.a. (Aus\$, 2007) if CityRail services were removed. 
A preliminary study was conducted by Thornton (2001) for the scoping study of a very high speed train in Eastern Australia. This used a road decongestion value of 28 cents per car kilometer (Aus\$, 2001) diverted to rail in metropolitan areas.

The Department of Infrastructure, Victoria, in 2005 (cited in ATC 2006) suggests a generalized unit decongestion value of 17 to 90 cents (Aus\$, 2004) per vehiclekilometer $(\mathrm{vkm})$ of reduced car travel. The value covers both time and vehicle operating cost changes.

Estimates of decongestion benefits (the reduced congestion costs experienced by remaining road users due to removal of a marginal vehicle) were made by Land Transport New Zealand (2005). The average congestion cost saving was Auckland NZ\$1.190/vkm and Wellington NZ $\$ 0.911 / \mathrm{vkm}$. This is adjusted for induced traffic effects.

\section{European Evidence}

A procedure for assessing the road decongestion benefits arising from the reduction in car traffic was developed by the UK Department for Transport (2007). This study valued the decongestion benefit as the savings of travel time and other externalities due to the removal of a vehicle kilometer of car travel from a road. The marginal external costs for cars were considered as the decongestion benefits. Decongestion benefits were estimated for " $A$ " (or major) Roads as 53.4 pence (UKE, 2007) per km (including travel time and vehicle operating costs) and 98.4 pence (UKE, 2007) per vkm (including travel time penalty, vehicle operating costs and other externalities such as accidents, noise, infrastructure damage, local air quality and greenhouse gases).

According to Sansom et al. (2001), the congestion benefits of "major-rail based urban public transport" per car-kilometer removed from the road network range from 12.7 to 50.8 pence per PCU-km (in 1998 prices; $\mathrm{PCU}=$ passenger car unit).

In his study for estimating congestion costs of Britain, Newbery (1990) used values derived from the marginal congestion cost associated with traffic speed-flow relationships. Marginal congestion cost estimates ranged from $0.26 \mathrm{p} / \mathrm{PCU}-\mathrm{km}$ for motorways to $36.37 \mathrm{p} / \mathrm{PCU}-\mathrm{km}$ (UKE, 1990) for urban central peak roads.

Lobe (2002) estimated the congested costs of Brussels by using STRATEC demand models. The model estimated a marginal congestion cost (i.e., the benefits of removing a marginal vehicle from the traffic stream) of $0.09 €$ per PCU-km (2002). 


\section{North American Evidence}

Research estimating congestion reduction benefits from reduced vehicle traffic by Litman $(2003,2006)$ reviewed several measurement methods and proposed an "easier approach." The approach is to assign a monetary value to reduced vehicle travel, typically estimated at 10-30 cents (US\$, 1996) per urban peak vehicle-mile, for calculating congestion reduction benefits. Skolnik and Schreiner (1998) used the midpoint of Litman's value ( 20 cents) for congestion benefit calculation of public transport.

Marginal costs of roadway use studied by FHWA (2000) reflect the changes in total costs associated with an additional increment of travel. The study estimated the congestion costs associated with an additional mile of travel on an urban interstate highway for passenger vehicles as 7.7 cents (i.e., 4.8 cents per kilometer) (US\$, 2000).

The average congestion reduction benefits for 85 US cities (Schrank and Lomax 2005) can be estimated as 42.0 cents per mile / 26.1 cents per $\mathrm{km}$ of reduced auto travel (US\$, 2005) by considering 18,243 millions of congestion reduction benefits resulting from 43,403 passenger-miles of public transport travel (Table 1) (a one-to-one relationship has been assumed between auto and public transport passenger miles). Using similar assumptions, the congestion reduction benefits of $\$ 736$ million (Nelson et al. 2006) for public transport in Washington, D.C., can be interpreted as 20.4 cents (US\$, 2000) per km of reduced auto travel.

\section{Synthesis of Congestion Relief Values}

Table 3 presents a summary of the evidence presented above. Results have been standardized to comparable terms by adjusting for currency (to Australian dollars) and year of estimate (using Australian CPI indices). Standardized values show a considerable range. Congestion impacts per reduced car $\mathrm{km}$ range between 4.4 and 151.4 cents, with an average of 45.0 cents. The highest valuations are associated with " $A$ " roads in Greater London and also for "heavy congestion" in the Melbourne, Australia, context. In both of these cases, travel time and vehicle operating cost impacts have been considered. The lower valuations of congestion relief impacts are associated with Christchurch, UK, motorways and non-major roads of small urban areas, and U.S. urban interstate highways. One possible explanation for low congestion relief benefit values for small urban areas is that they witness a relatively low volume of traffic in comparison to their big counter- 


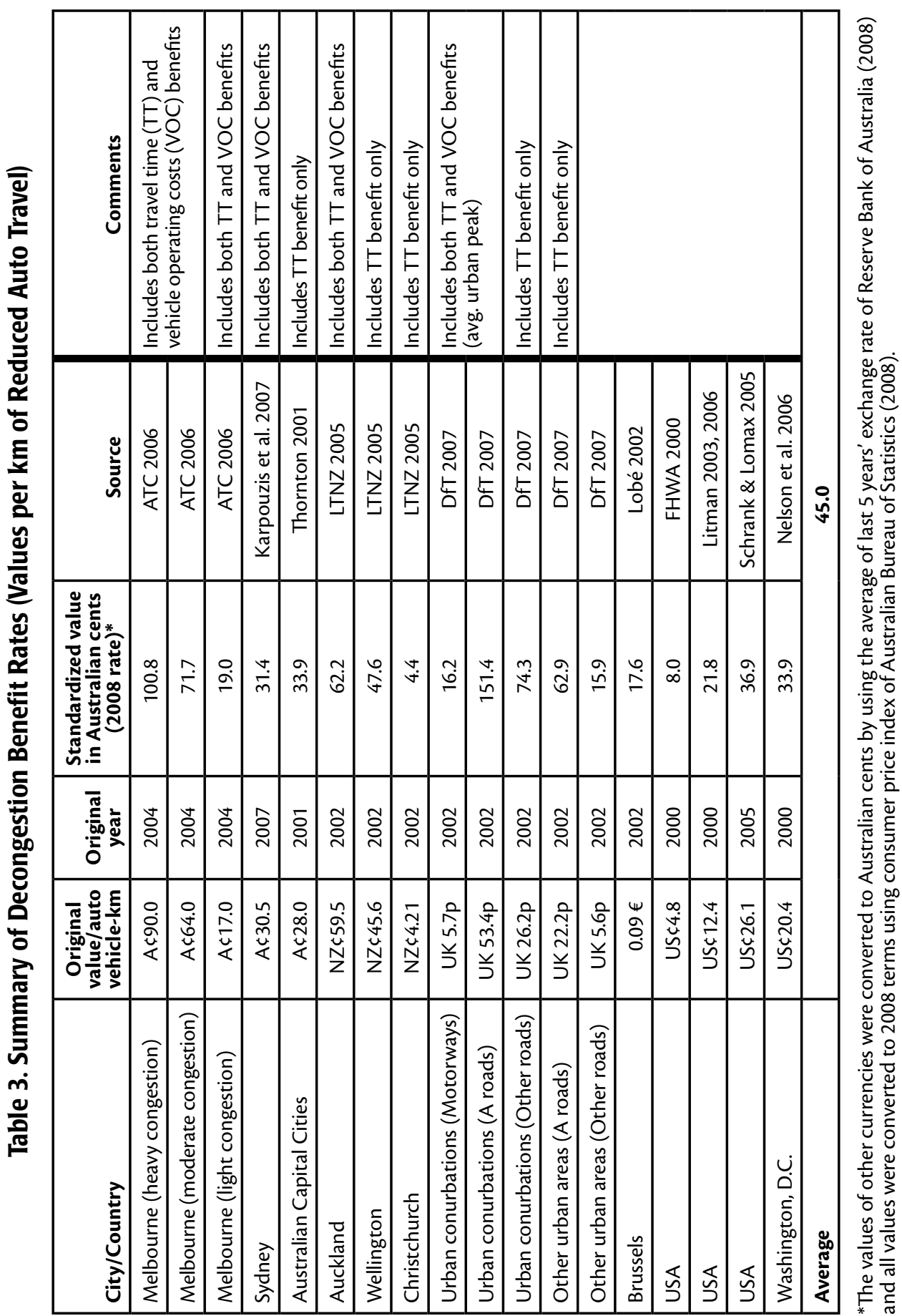


parts and, hence, the unit congestion relief benefits are less. UK motorways and U.S. urban interstate highways have relatively high capacity compared to roads in urban central areas and, therefore, unit congestion relief benefits are small. Figure 1 illustrates the average decongestion value assuming a simple linear relationship with transit supply.

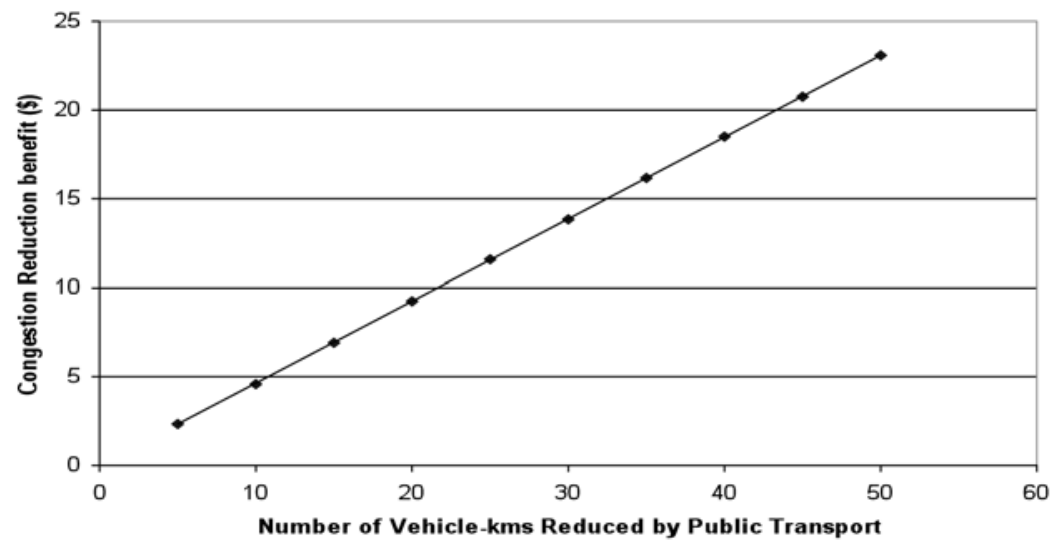

\section{Figure 1. Congestion Reduction Benefit Resulting from Reduction of Auto Vkm Due to Public Transport}

\section{Travel Mode Shift Evidence}

This section examines revealed and stated evidence where travel behavior acted to change urban traffic congestion in relation to public transport. Its aim is to establish evidence that might better inform the assessment of congestion relief impacts.

\section{Removing Public Transport}

Cases where public transport systems have been removed are examined. Van Exel and Rietveld (2001) reviewed 13 studies of PT strikes to determine nature and size of travel impacts. Their study showed that most travelers switch to the car either as driver or passenger (Table 4a). Other travelers switch to alternative modes and some trips are cancelled. Mode shift to car driving was 5 to 50 percent (average $28.6 \%$ ), mode shift to car lift was 21 to 60 percent (average 29.6\%), shift to other modes was 23 to 60 percent (average $39.8 \%$ ), and trip suppression (stop travelling) was between 5 and 15 percent (average 10.3\%). 


\section{Table 4. Evidence of Impacts of Removing Public Transport}

4a. Effects of public transport strikes

\begin{tabular}{|c|c|c|c|c|c|c|c|}
\hline \multirow[b]{2}{*}{ Strike } & \multirow[b]{2}{*}{ Year } & \multirow{2}{*}{$\begin{array}{l}\text { Spatial } \\
\text { scale }\end{array}$} & \multirow{2}{*}{$\begin{array}{c}\text { PT } \\
\text { modes }\end{array}$} & \multicolumn{2}{|c|}{$\begin{array}{c}\text { Trips switched } \\
\text { to car }\end{array}$} & \multirow{2}{*}{$\begin{array}{c}\text { Trips switched } \\
\text { to other } \\
\text { alternatives }\end{array}$} & \multirow{2}{*}{$\begin{array}{c}\text { Trips } \\
\text { cancelled }\end{array}$} \\
\hline & & & & Driver & Pax & & \\
\hline New York & 1966 & Urban & All & $50 \%$ & $17 \%$ & $23 \%$ & $10 \%$ \\
\hline Los Angeles & 1974 & Regional & Bus & $50 \%$ & $25 \%$ & $\ldots$ & $\ldots$ \\
\hline Leeds & 1978 & Urban & All & $5 \%$ & $60 \%$ & $35 \%$ & $15 \%$ \\
\hline The Hague & 1981 & Urban & All & $10 \%$ & $25 \%$ & $50 \%$ & $5 \%$ \\
\hline Ile-de-France & 1995 & Regional & All & $28 \%$ & $21 \%$ & $51 \%$ & $11 \%$ \\
\hline Average & & & & $28.6 \%$ & $29.6 \%$ & $39.8 \%$ & $10.3 \%$ \\
\hline
\end{tabular}

Source: HLB Decision Economics (2003)

4b. Alternative transport modes for those individuals who responded they would make the same trip via an alternative mode if public transport withdrawn

\begin{tabular}{|l|c|c|c|c|}
\hline Journey purpose & $\begin{array}{c}\text { Use other means } \\
\text { of transport }\end{array}$ & $\begin{array}{c}\text { Driving } \\
\text { car }\end{array}$ & $\begin{array}{c}\text { Sharing } \\
\text { car/taxi }\end{array}$ & $\begin{array}{c}\text { Walking, cycling } \\
\text { and other }\end{array}$ \\
\hline Work & $48.0 \%$ & $10.7 \%$ & $19.2 \%$ & $18.1 \%$ \\
\hline Education & $48.0 \%$ & $10.7 \%$ & $19.2 \%$ & $18.1 \%$ \\
\hline Healthcare & $47.5 \%$ & $10.5 \%$ & $19.0 \%$ & $18.0 \%$ \\
\hline Shopping and recreation & $32.7 \%$ & $7.3 \%$ & $13.1 \%$ & $12.3 \%$ \\
\hline Average & & $\mathbf{9 . 8} \%$ & $\mathbf{1 7 . 6 \%}$ & $\mathbf{1 6 . 7 \%}$ \\
\hline
\end{tabular}

Source: HLB Decision Economics (2003)

In a study examining the choices that public transport riders might make, HLB Decision Economics (2003) conducted a survey in Wisconsin. Each individual was asked to indicate how their travel would differ if they did not have access to public transport. The study shows that about 50 percent of public transport users would make trips via an alternative transport mode. Of these, car or taxi would be the likely new mode for about 60 percent. Table $4 \mathrm{~b}$ summarizes the important elements of the study. The likely mode shift to car driving varied from 7 to 11 percent (average 9.8\%), mode shift to car/taxi riding as passengers varied from 13 to 19 percent (average 17.6\%), and walking, cycling, and other modes varied from 12 to 18 percent (average 16.7\%).

These studies demonstrate a range of variation in mode change behavior if public transport is no longer supplied. Overall, mode shift for car drivers ranged from 5 
to 50 percent (average 20.2\%) and mode shift for car passengers ranged from 13 to 60 percent (average $24.3 \%$ ) (Table 5).

Table 5. Summary of Mode Shift for Car Drivers and Passengers

\begin{tabular}{|l|c|c|c|c|}
\hline \multirow{2}{*}{ Source } & \multicolumn{2}{|c|}{ Mode shift (car drivers) } & \multicolumn{2}{c|}{ Mode shift (car passenger) } \\
\cline { 2 - 5 } & Range & Average & Range & Average \\
\hline Exel and Rietveld (2001) & $5 \%-50 \%$ & $28.6 \%$ & $21 \%-60 \%$ & $29.6 \%$ \\
\hline HLB Decision Economics (2003) & $7 \%-11 \%$ & $9.8 \%$ & $13 \%-19 \%$ & $17.6 \%$ \\
\hline Average $^{1}$ & & $\mathbf{2 0 . 2 \%}$ & & $\mathbf{2 4 . 3 \%}$ \\
\hline
\end{tabular}

${ }^{1}$ Average of values appeared in Tables $4 \mathrm{a}$ and $4 \mathrm{~b}$

Litman (2006) noted specific subsets of those passengers who might decide to get a lift by car. One group does ridesharing (additional passengers in a vehicle that would be making a trip anyway). The other group does chauffeuring (additional auto travel specifically to carry a passenger).

Litman suggested that motorists can spend a significant amount of time chauffeuring children to school and sports activities, family members to jobs, and elderly relatives on errands. Such trips can be particularly inefficient if they require drivers to make an empty return trip. Hence, while ex-public transport users who drive a car clearly have a direct impact on congestion, those getting lifts may also impact congestion if chauffeuring acts to also increase car travel.

Overall, this analysis suggests that removing public transport can result in increased traffic congestion of about a shift of 20.2 percent (Table 5) of public transport to car driving. However, the work of Litman also suggests that ex-public transport users might also generate extra car travel in the form of chauffeuring trips. Little data are available on how many ex-PT users in this context might be involved in chauffeuring trips. For the purpose of our modelling analysis, we assumed that half of all trips transferring to a lift in a car might involve chauffeuring. Hence, on average, based on the results in Table 5, an estimate of 32.4 percent (20.2\% car drivers + half of $24.3 \%$ car passengers as chauffeuring travelers) or approximately one-third of PT users might act to increase auto travel if the public transport system were removed. This interpretation should be used cautiously, as the proposed value is an average of a wide range of values from different cities of the world. A wide range of methodologies also have been applied to obtaining these values. In addition, public transport strikes manifest short-term effects. In the long term, the estimated percentage might be different because people will adjust their travel 
behavior to cope with the changed situation (such as trip re-timing, trip redistribution, changes of O-D pattern and travel behavior, etc.).

\section{Improving Public Transport}

This section considers evidence of mode shift associated with improvements in public transport. Anlezark et al. (1994) examined mode shift outcomes resulting from the introduction of new Transit Link (express bus services) in Adelaide, Australia. They also compiled evidence from other new public transport initiatives (Table 6a). They report that about 20 percent of users are new to public transport and of these the highest proportion are formerly car drivers. Mode shift from car drivers was from 8 to 23 percent (average 14.1\%), mode shift from car passengers was from 1 to 12 percent (average 5.7\%), trip generation was from 8 to 12 percent (average 9.8\%), and diversion from existing public transport was between 64 and 78 percent (average 68.5\%).

\section{Table 6. Evidence of Impacts of Improving Public Transport}

6a. Comparison of mode change behavior after the introduction of new public transport services

\begin{tabular}{|l|c|c|c|c|c|}
\hline \multirow{2}{*}{ New Service } & \multicolumn{4}{|c|}{ Source of Demand } \\
\cline { 2 - 3 } & \multicolumn{2}{|c|}{ Mode Shift } & & $\begin{array}{c}\text { Diversion } \\
\text { from PT }\end{array}$ & Redistribution \\
\cline { 2 - 5 } & Car driver & Car Pax & Generation & $\mathbf{4} \%$ & $1 \%$ \\
\hline Adelaide-Express Bus & $8.4 \%$ & $4.4 \%$ & $8 \%$ & $78 \%$ & $0 \%$ \\
\hline Adelaide-Obahn Busway & $13.3 \%$ & $5.7 \%$ & $9 \%$ & $67 \%$ & $0 \%$ \\
\hline Brisbase Cityxpress & $11.6 \%$ & $11.6 \%$ & $12 \%$ & $65 \%$ & $1 \%$ \\
\hline Perth Northern Railway & $23.0 \%$ & $1.1 \%$ & $10 \%$ & $64 \%$ & \\
\hline Average & $\mathbf{1 4 . 1} \%$ & $\mathbf{5 . 7 \%}$ & $\mathbf{9 . 8 \%}$ & $\mathbf{6 8 . 5} \%$ & \\
\hline
\end{tabular}

Source: Anlezark et al. (1994)

6b. Travel market data for Australasian BRT systems

\begin{tabular}{|l|l|c|c|}
\hline \multirow{2}{*}{} & \multicolumn{3}{|c|}{ Immediate Travel Impacts } \\
\cline { 2 - 4 } & $\begin{array}{c}\text { Direct corridor } \\
\text { ridership growth }\end{array}$ & $\begin{array}{c}\% \text { new pax who } \\
\text { previously drove }\end{array}$ & $\begin{array}{c}\% \text { who previously drove } \\
\text { as a total of all riders }\end{array}$ \\
\hline Adelaide Busway & $24 \%$ & $40 \%$ & $16 \%$ \\
\hline Sydney Transitway & $56 \%(47 \%$ new journeys) & $9 \%$ & $5 \%$ \\
\hline Brisbane SE Busway & $56 \%(17 \%$ new journeys) & $26 \%$ & $15 \%$ \\
\hline Average & & $\mathbf{1 1 . 9 \%}$ & \\
\hline
\end{tabular}

Source: Currie (2006) 


\section{Table 6. Evidence of Impacts of Improving Public Transport (cont'd.)}

6c. Prior mode for new public transport riders-fare reduction and service improvement

\begin{tabular}{|l|c|c|c|c|c|}
\hline \multirow{2}{*}{ Location } & \multicolumn{5}{|c|}{ Prior Mode } \\
\cline { 2 - 6 } & Auto Driver & Auto Passenger & Walk & Other & Trip Not Made \\
\hline Atlanta & $42 \%$ & $22 \%$ & $4 \%$ & $10 \%$ & $22 \%$ \\
\hline Los Angeles & $59 \%$ & $21 \%$ & $0 \%$ & $10 \%$ & $10 \%$ \\
\hline Average & $\mathbf{5 0 . 5 \%}$ & $\mathbf{2 1 . 5} \%$ & & & \\
\hline
\end{tabular}

Source: McCollom and Pratt (2004)

A review of performance of Bus Rapid Transit (BRT) in Australasia by Currie (2006) reveals that introduction of $B R T$ played a significant role in changing travel behavior (Table 6b). BRT passengers who were previously driving is high in Adelaide (40\%). Mode shift from car drivers was from 5 to 16 percent (average 11.9\%).

A number of studies have sought to understand mode shift impacts from fare reduction and service increase policies in the U.S. (McCollom and Pratt 2004). These studies show diversion from auto ranging from 64 percent of new riders in Atlanta to 80 percent of new riders in Los Angeles. The full range of previous modes of travel is shown in Table 6c. Mode shift for car drivers was from 42 to 59 percent (average 50.5\%), mode shift for car passengers was from 21 to 22 percent (average 21.5\%).

Again, a range of variation can be observed. Overall, mode shift for car drivers ranged from 5 to 59 percent (average 21.4\%), and mode shift for car passengers ranged from 1 to 22 percent (average 11.0\%) (Table 7). Passengers who change mode from car driving to transit clearly act to reduce traffic congestion. Considering the view of Litman (2006) that chauffeuring trips act to increase car travel, it might again be assumed that a travel shift from a car lift trip to transit might also reduce car travel. For the purpose of analysis, the data suggest that 26.9 percent of travelers ( $21.4 \%$ car drivers + half of $11.0 \%$ car passengers as chauffeuring travelers) on new public transport services might have acted to reduce road travel (Table 7). This is lower than the impact suggested for removing public transport (32.4\%). A higher impact for removing transit systems compared to improving seems intuitively reasonable. Withdrawal of PT means users have no choice but to make a change in behavior. Improvements leave an element of user choice in deciding travel options and will largely depend in scale on the size of improvements being made. Figure 2 illustrates this relationship as a simple linear model based on this relationship. 
Table 7. Summary of Mode Shift for Car Drivers and Passengers

\begin{tabular}{|l|c|c|c|c|}
\hline \multirow{2}{*}{ Source } & \multicolumn{2}{|c|}{ Mode shift (car drivers) } & \multicolumn{2}{c|}{ Mode shift (car passenger) } \\
\cline { 2 - 5 } & Range & Average & Range & Average \\
\hline Anlezark et al. (1994) & $8 \%-23 \%$ & $14.1 \%$ & $1 \%-12 \%$ & $5.7 \%$ \\
\hline Currie (2006) & $5 \%-15 \%$ & $11.9 \%$ & $\ldots .-3$ & $\ldots . .3$ \\
\hline McCollom and Pratt (2004) $^{3}$ & $42 \%-59 \%$ & $50.5 \%$ & $21 \%-22 \%$ & $21.5 \%$ \\
\hline Average $^{2}$ & & $\mathbf{2 1 . 4 \%}$ & & $\mathbf{1 1 . 0 \%}$ \\
\hline
\end{tabular}

${ }^{1}$ Average of values appeared in TABLE $6 \mathrm{a}, \mathrm{b}$ and $\mathrm{c}$

${ }^{2}$ Data unavailable

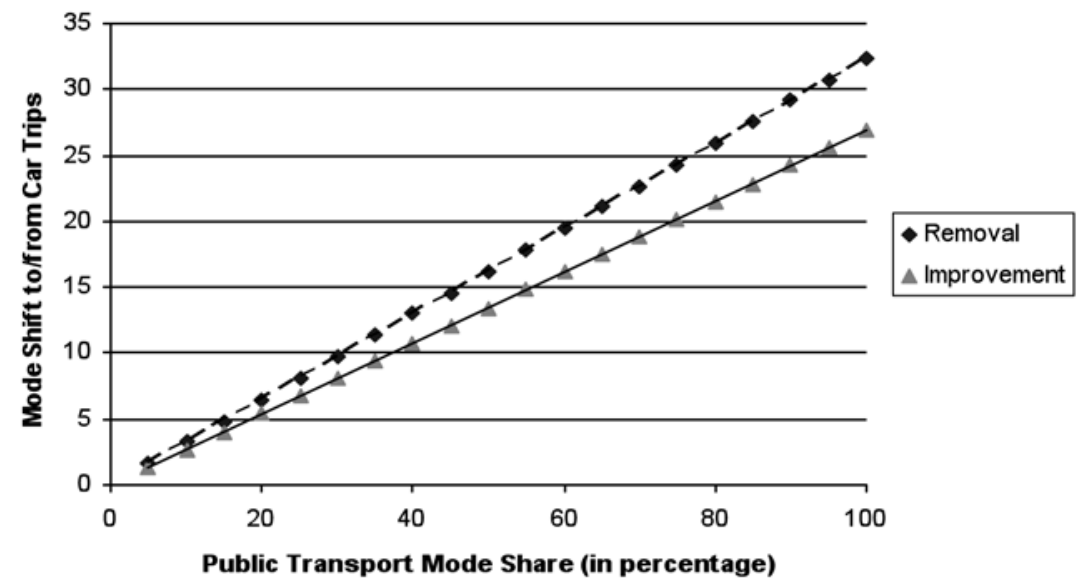

Figure 2. Relationship Between Mode Shift to/from Car and Public Transport Mode Share

\section{Application of a Simplified Congestion Relief Valuation Model}

This section models the congestion relief benefits of public transport for a number of cities by applying the evidence assembled in the previous sections. The aim is to present a simplified congestion relief valuation model and to illustrate the application of this model. The performance of public transport to relieve traffic congestion depends on many city and transport variables such as population, trip rate, mode share, average trip distance, city size and density, land use, development patterns, topography, the roadway network and public transport system, existing levels of congestion, socio-economic status of users and non-users, overall travel 
pattern and telecommuting, peak spreading, and so on. Each of those variables can be viewed as a dimension of a hyper-cube. If the impacts of those variables are to be considered, it is necessary to specify values for numerous combinations of those variables. Six parameters for this model are selected to demonstrate a practical method with easily available data for most cities. A simple model is proposed of the following form:

$$
D C B_{P T}=P \times T R \times P T_{\text {share }} \times D \times M S \times D B
$$

Where,

$D C B_{P T}=$ Annual decongestion benefit of public transport in a city

$P=$ population

$T R=$ average trip rate (trips per person per annum)

$P T_{\text {share }}=$ Public transport mode share

$D=$ average trip distance

$M S=$ Percentage of mode shift (additional auto travel for removal of $P T$ )

$D B=$ Unit value of decongestion benefits

The simplified congestion relief valuation model has been used to a group of cities covering a wide range of sizes throughout the world have been used. Sixty cities from "Millennium Cities Database" (Kenworthy and Laube, 2001) were selected for the analysis. The cities from developing Asian and African countries were not included in this study because the nature of transit provision and car ownership of these cities differs substantially from those of the selected cities from the developed countries. In this database, per capita annual public transport passenger-km of travel $\left(P T_{P K T}\right)$ is available. This $P T_{P K T}$ can be use as a combined term for $T R$, $P T_{\text {share }}$, and $D$ of the equation 1. Thus equation 1 takes the form of equation 2. 


$$
D C B_{P T}=P \times P T_{P K T} \times M S \times D B
$$

Where,

$D C B_{P T}=$ Annual decongestion benefit of public transport in a city (Aus\$, 2008 value)

$\mathrm{P}=$ population

PTPKT = Per capita annual public transport passenger-km of travel

$M S=$ Proportion of mode shift (additional auto travel for removal of PT) $=1 / 3$

$\mathrm{DB}=$ Unit value of decongestion benefits $=\$ 45.0($ Aus $\$ 2008)$

Modeling considers the cost impacts of removing public transport for global cities. Key parameters include:

- the mode shift impacts of removing public transport-in this case, we have assumed the average of the evidence presented in the previous section, i.e., an estimate of 32.4 percent of PT travel would end up using roads (including $20.2 \%$ car drivers + half of $24.3 \%$ car passengers as chauffeuring travelers), i.e., approximately one third of PT travelers.

- The unit value of congestion costs - in this case, we have assumed $45.0 \mathrm{c} \mathrm{per}$ additional vehicle $\mathrm{km}$ based on the average of the analysis in Table 3.

Table 8 shows the estimated congestion relief values of public transport in millions of Australian dollars (2008). It indicates that European and developed Asian cities feature prominently in congestion relief impact of public transport. The congestion relief values of some these cites exceeds $\$ 1$ billion per annum. These values certainly give insight how public transport act to relieve congestion in global cities and facilitate cross-city comparison in terms of congestion relief impact. 
Table 8. Estimated Congestion Relief Benefit of Public Transport for Global Cities

\begin{tabular}{|c|c|c|c|c|}
\hline City & City population $(M)$ & PT pax-km per capita & Congestion Relief Value (M\$) & Rank \\
\hline Tokyo & 32.34 & 5,605 & 27,192 & 1 \\
\hline Osaka & 16.83 & 6,011 & 15,175 & 2 \\
\hline Moscow & 10.38 & 7,153 & 11,137 & 3 \\
\hline New York & 19.23 & 1,266 & 3,651 & 4 \\
\hline Hong Kong & 6.31 & 3,675 & 3,478 & 5 \\
\hline Paris & 11.00 & 1,763 & 2,909 & 6 \\
\hline London & 7.01 & 2,047 & 2,153 & 7 \\
\hline Rome & 2.65 & 3,805 & 1,512 & 8 \\
\hline Singapore & 2.99 & 3,143 & 1,409 & 9 \\
\hline Madrid & 5.18 & 1,454 & 1,129 & 10 \\
\hline Ruhr & 7.36 & 987 & 1,090 & 11 \\
\hline Budapest & 1.91 & 3,627 & 1,039 & 12 \\
\hline Berlin & 3.47 & 1,736 & 903 & 13 \\
\hline Sydney & 3.74 & 1,509 & 847 & 14 \\
\hline Prague & 1.21 & 4,321 & 784 & 15 \\
\hline Chicago & 7.52 & 688 & 776 & 16 \\
\hline Barcelona & 2.78 & 1,764 & 735 & 17 \\
\hline Toronto & 4.63 & 1,050 & 730 & 18 \\
\hline Stockholm & 1.73 & 2,317 & 601 & 19 \\
\hline Milan & 2.46 & 1,480 & 546 & 20 \\
\hline Munich & 1.32 & 2,622 & 519 & 21 \\
\hline Athens & 3.46 & 958 & 497 & 22 \\
\hline Montreal & 3.22 & 993 & 480 & 23 \\
\hline Sapporo & 1.76 & 1,789 & 472 & 24 \\
\hline Melbourne & 3.14 & 994 & 468 & 25 \\
\hline San Francisco & 3.84 & 810 & 466 & 26 \\
\hline Copenhagen & 1.74 & 1,704 & 445 & 27 \\
\hline Los Angeles & 9.08 & 326 & 444 & 28 \\
\hline Washington & 3.74 & 781 & 438 & 29 \\
\hline Vienna & 1.59 & 1,642 & 392 & 30 \\
\hline Hamburg & 1.70 & 1,446 & 369 & 31 \\
\hline Zurich & 0.79 & 2,503 & 297 & 32 \\
\hline Glasgow & 2.18 & 884 & 289 & 33 \\
\hline
\end{tabular}


Table 8. Estimated Congestion Relief Benefit of Public Transport for
Global Cities (cont'd)

\begin{tabular}{|c|c|c|c|c|}
\hline City & City population (M) & PT pax-km per capita & Congestion Relief Value (M\$̦) & Rank \\
\hline Helsinki & 0.89 & 1,970 & 263 & 34 \\
\hline Brussels & 0.95 & 1,613 & 230 & 35 \\
\hline Manchester & 2.58 & 541 & 209 & 36 \\
\hline Oslo & 0.92 & 1,512 & 209 & 37 \\
\hline Newcastle & 1.13 & 1,167 & 198 & 38 \\
\hline Cracow & 0.74 & 1,772 & 197 & 39 \\
\hline Brisbane & 1.49 & 720 & 161 & 40 \\
\hline Atlanta & 2.90 & 358 & 156 & 41 \\
\hline Amsterdam & 0.83 & 1,136 & 141 & 42 \\
\hline Berne & 0.30 & 3,114 & 140 & 43 \\
\hline Ottawa & 0.97 & 851 & 124 & 44 \\
\hline Perth & 1.24 & 642 & 119 & 45 \\
\hline Stuttgart & 0.59 & 1,344 & 119 & 46 \\
\hline Frankfurt & 0.65 & 1,167 & 114 & 47 \\
\hline Houston & 3.92 & 184 & 108 & 48 \\
\hline Calgary & 0.77 & 925 & 107 & 49 \\
\hline Dusseldorf & 0.57 & 1,205 & 103 & 50 \\
\hline Lyon & 1.15 & 550 & 95 & 51 \\
\hline San Diego & 2.63 & 206 & 81 & 52 \\
\hline Marseille & 0.80 & 540 & 65 & 53 \\
\hline Nantes & 0.53 & 798 & 63 & 54 \\
\hline Denver & 1.98 & 205 & 61 & 55 \\
\hline Graz & 0.24 & 1,564 & 56 & 56 \\
\hline Geneva & 0.40 & 774 & 46 & 57 \\
\hline Bologna & 0.45 & 666 & 45 & 58 \\
\hline Vancouver & 0.37 & 767 & 43 & 59 \\
\hline Phoenix & 2.53 & 100 & 38 & 60 \\
\hline
\end{tabular}

\section{Conclusion}

The paper has presented a comparative assessment of international research valuing the congestion relief benefits of public transport. It also has explored previous research methodologies evaluating congestion relief impacts and examined sec- 
ondary evidence demonstrating changes in mode split associated with changes in public transport.

Congestion relief impacts are valued at between 4.4 and 151.4 cents (Aus\$, 2008) per marginal vehicle $\mathrm{km}$ of travel, with an average of 45.0 cents. Valuations are higher for circumstances with greater degrees of traffic congestion and also where both travel time and vehicle operating cost savings are considered.

Mode shift evidence suggests on average some 21 percent of PT trips might be attracted to PT from car drivers (or could be returned to car driving if PT were removed). On average, around 11 to 24 percent of passengers getting a lift have been encouraged onto PT (or might return to getting a lift if PT were removed). It is estimated that approximately one third of PT travelers lead to additional car travel in the case of its removal (this mode shift value is the summation of car drivers and half of car passengers as chauffeuring travelers).

A simplified congestion relief model is presented to value the congestion relief benefits of PT based on readily available data. Using the average congestion valuation and mode shift evidence this model has been applied to a number of cities to estimate congestion relief values. A model of this type could be applied for studies at a city scale but would also be of value to localized corridor studies and smaller scale reviews evaluating infrastructure investment proposals.

A range of areas for further analysis are suggested by the research:

- A linear relationship between the unit benefit of congestion reduction and the number of users has been assumed but in reality, the unit congestion unit is expected to vary at different level of number of users.

- The values shown in this paper for the effects of PT removal/improvement are short-term in nature, and further research can be carried out to distinguish between the short-term and long-term effects.

- The paper does not consider the effects of land use change, existing levels of congestion, socio-economic status of users and non-users, overall travel pattern and telecommuting, peak spreading, and other related issues. The model in the previous section can be extended by including the effects of these variables.

In addition to the above, research in this field needs to be mindful of wider research concerning both the value of time and the value of reliability related benefits to both road users and public transport users. Value of time is a critical 
input to any economic assessment of congestion relief. Travel and waiting time reliability is also critically influenced by traffic congestion and is a component not directly considered in the research reported here. Clearly, research in these areas has a role in informing discussion about congestion impacts.

Overall, the analysis presents a simplified method to investigate the impact of public transport on traffic congestion. Further research is warranted to develop a comprehensive approach for establishing a measure of the congestion relief impacts of public transport.

\section{Acknowledgments}

The authors would like to acknowledge the support provided for the research by Monash University in the form of Monash Graduate Scholarship. In addition, we thank the two anonymous reviewers of this paper for their useful suggestions and comments for improving the quality of the paper. Any errors and omissions are the responsibility of the authors.

\section{References}

Anlezark, A., B. Crouch, and G. V. Currie. 1994. Trade-offs in the redesign of public transport networks, line haul, express and transit link service patterns. 19th Australasian Transport Research Forum. Perth: Planning and Transport Research Centre.

Australian Bureau of Statistics. Consumer Price Index. http://www.abs.gov.au/ AUSSTATS/abs@.nsf/mf/6401.0. (accessed July 23, 2008).

Australian Transport Council (ATC). 2006. National Guidelines for Transport System Management in Australia: UrbanTtransport. Vol. 4. Canberra: ATC.

Beimborn, E., A. Horowitz, J. Schuetz, and G. Zejun. 1993. Measurement of transit benefits. Prepared by the Center for Urban Transportation Studies, University of Wisconsin-Milwaukee, for Federal Transit Administration, Washington, D.C.

Cambridge Systematics Inc. and Apogee Research Inc. 1996. Measuring and valuing transit benefits and disbenefits. TCRP Report 20. Washington, D.C.: Transportation Research Board.

Cervero, R. 1998. The Transit Metropolis: A Global linquiry. Washington, D.C: Island Press. 
Currie, G. 2006. Bus rapid transit in Australasia: Performance, lessons learned and futures. Journal of Public Transportation 9 (3): 1-22.

Department for Transport. 2007. Transport Analysis Guidance-Unit 3.9.5: MSA Major Schemes Appraisal of Road Decongestion Benefits. London: Department for Transport.

Downs, A. 1992. Stuck in Traffic: Coping with Peak-Hour Traffic Congestion. Washington, D.C.: The Brookings Institution.

ECONorthwest and PBQD. 2002. Estimating the benefits and costs of public transport projects: A guidebook for practitioners. TCRP Report 78. Washington, D.C.: Transportation Research Board.

Federal Highway Administration (FHWA). 2000. Addendum to the 1997 federal highway cost allocation study. Final Report. Washington, D.C.: FHWA.

HLB Decision Economics Inc. 2003. The socio-economic benefit of transit in Wisconsin. Final Report No. 0092-03-07. Wisconsin: Wisconsin Department of Transportation.

Hyman, G., and L. Mayhew. 2002. Optimizing the benefits of urban road user charging. Transport Policy 9(3): 189-207.

Kenworthy, J. R., and F. B. Laube. 2001. The millennium cities database for sustainable transport. CD format. Brussels: International Association of Public Transport (UITP).

Karpouzis, G., A. Rahman, K. Tandy, and C. Taylor. 2007. Value of CityRail to the community of New South Wales. 30th Australasian Transport Research Forum. Perth: Planning and Transport Research Centre.

Land Transport New Zealand (LTNZ). 2005. Economic Evaluation Manual. Volume 2. Wellington: LTNZ.

Litman, T. 2003. Transportation Cost and Benefit Analysis Guidebook-Congestion Costs. Victoria: Victoria Transport Policy Institute.

Litman, T. 2006. Rail Transit in America: A Comprehensive Evaluation of Benefits. Victoria: Victoria Transport Policy Institute.

Lobe, P. 2002. UNITE: Case studies 7E-Brussels urban transport. Prepared by ITS, University of Leeds, for UNITE (UNIfication of accounts and marginal costs for Transport Efficiency) Working Funded by 5th Framework RTD Program, Brussels. 
McCollom, B. E., and R. H. Pratt. 2004. Traveler response to transportation system changes: Chapter 12- Transit pricing and fares. TCRP Report 95. Washington, D.C.: Transportation Research Board.

Nelson, P., A. Baglino, W. Harrington, E. Safirova, and A. Lipman. 2006. Transit in Washington, D.C.: Current benefits and optimal level of provision. Discussion Paper. RFF DP 06-21. Washington, D.C.: Resource for the Future.

Newbery, D. M. 1990. Pricing and congestion: Economic principles relevant to pricing roads. Oxford Review of Economic Policy 6(2): 22-38.

Pucher, J., Z. Peng, N. Mittal, Y. Zhu, and N. Korattyswaroopam. 2007. Urban transport trends and policies in China and India: Impacts of rapid economic growth. Transport Reviews 27(4): 379-410.

Reserve Bank of Australia. Historical Exchange Rates. http://www.rba.gov.au/Statistics/ HistoricalExchangeRates/index.html (accessed July 23, 2008).

Sansom, T., C. Nash, P. Mackie, J. Shires, and P. Watkiss. 2001. Surface transport costs and charges: Great Britain 1998. Prepared by Institute of Transport Studies, University of Leeds, for the UK Department of the Environment, Transport and the Regions (DETR).

Schrank, D., and T. Lomax. 2005. The 2005 Annual Urban Mobility Report. College Station, Texas: Texas Transportation Institute, The Texas A\&M University System.

Skolnik, J., and R. Schreiner. 1998. Benefits of Transit in Small Urban Areas: A Case Study. Transportation Research Record: Journal of the Transportation Research Board 1623: 47-56.

Thornton, P. B. East coast very high speed train scoping study. Phase 1- Preliminary study, final report. Prepared by ARUP and TMG International Pty Ltd, for Department of Infrastructure, Transport, Regional Development and Local Government, Canberra, 2001.

Van Exel, N.J.A.V., and P. Rietveld. 2001. Public transport strikes and traveller behaviour. Transport Policy 7(3): 227-246.

Vuchic, V. R. 1999. Transportation for Livable Cities. New Brunswick, New Jersey: Rutgers Center for Urban Policy Research.

Weisbrod, G., D. Vary, and G. Treyz. Economic implications of congestion. NCHRP Report 463. Washington, DC.: Transportation Research Board. 


\section{About the Authors}

Md Aftabuzzaman (md.aftabuzzaman@eng.monash.edu.au) is currently pursuing a Ph.D. in Transport Planning at the Institute of Transport Studies, Monash University, Australia. He holds a bachelor's degree in Civil Engineering from Bangladesh University of Engineering and Technology (BUET), Dhaka and a master's degree in Urban Transport Planning from The University of Tokyo, Japan. Prior to commencing his graduate study at Monash University, he worked for the Department of Urban and Regional Planning, BUET. His research and consultation interests include public transport operation and planning, traffic performance measurement, transport demand modeling, mode choice analysis, and parking demand and supply analysis.

Professor Graham Currie (graham.currie@eng.monash.edu.au) holds Australia's first professorship in public transport where he researches and provides training in public transport planning. He has over 27 years' experience as a transit planner and has worked for some of the worlds leading operators including London Transport. He has led numerous research projects in public transport in all states and territories of Australia as well as assignments in Europe, Asia and North America and has a unique range of experience in relation to the development of Public Transport strategies for Special Events. He developed the public transport plan for the successful 1996 Australian Grand Prix, led independent reviews of both the Atlanta and Sydney summer Olympic Games transport systems, and was an advisor to the Athens Olympic Committee for the design of transport services for the 2004 Olympic Games.

DR. MAJID SARVI (majid.sarvi@eng.monash.edu.au) is a senior lecturer of the Institute of Transport Studies, Monash University. Prior to joining at Monash University, he worked as a research fellow in Tokyo University, chief researcher of ITS research group of Social System Research Institute in Japan, and transport analyst with Hong Kong Transport Department. His research interests include traffic operations, transit planning, traffic flow theory, microsimulation, transport modeling, and highway operations. He has written more than 40 articles in refereed journals, book chapters, and proceedings of refereed conferences and holds a B.Eng. from Tehran University and an M.Eng. and Ph.D. from Tokyo University. 